\title{
Graphic map load comparison of two Czech school atlases using edge detection
}

\author{
Radek Barvir $^{\mathrm{a}, *}$, Vit Vozenilek ${ }^{\mathrm{a}}$ \\ ${ }^{a}$ Palacký University Olomouc, Faculty of Science, Department of Geoinformatics, Radek Barvir - radek.barvir@ upol.cz, Vit \\ Vozenilek - vit.vozenilek@upol.cz. \\ * Corresponding author
}

Keywords: map load, map complexity, school atlases, map evaluation, edge detection

\begin{abstract}
:
Map complexity has been studied by cartographers for decades. Unfortunately, it is not being systematically measured as an essential map property and used to optimize cartographic products during the map-making process. Therefore, the appropriate load of map content in a map usually remains dependent only on the subjective assessment of the cartographer designing the map.
\end{abstract}

The paper aims to describe and examine newly developed easy-to-use metric for graphic map load evaluation. A plugin for an open-source software Gimp was developed to provide an accessible tool to measure graphic map load of various geospatial visualizations in an image file format. This tool was then used to compare two Czech school atlases produced by Kartografie PRAHA, a.s. publisher in terms of their graphic map load. The examined atlases include: the latest World School Atlas (in Czech Školní atlas světa) and the new equivalent called Pupil's Atlas (originally Školní atlas světa) intended to fit especially to younger pupils. Both the atlases are captured in Figure 1.
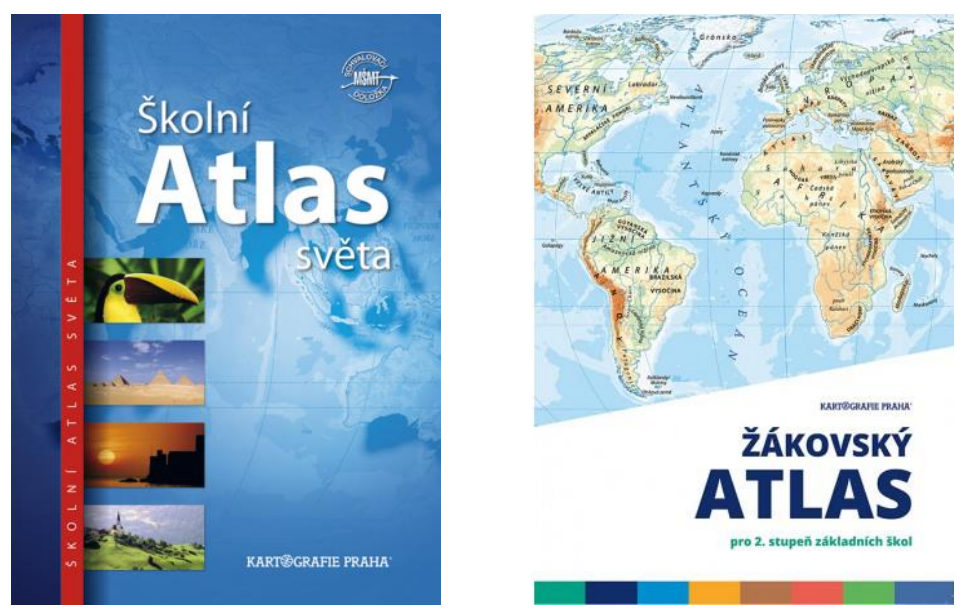

Figure 1. Cover of examined atlases: World School Atlas (left) and Pupil's Atlas (right), source: Kartografie PRAHA, a.s.

The equivalent maps (the same or very similar map extents, scales, captured regions and map types) in both atlases were compared to investigate differences in graphic map load. For this, a developed metric implemented in the form of an extension to well-known image processing software Gimp was used. The extension advances an edge detection filter to identify both sharp and smooth edges in order to estimate the graphic map load of map samples. Also, a distribution of map load across the map layout is shown. Subsequently, measured values were compared and used to estimate the differences in the potential readability of those products.

\section{Acknowledgements}

The paper was compiled within the Czech Scientific Foundation project No 18-05432S „Spatial synthesis based on advanced geocomputation methods". 